\title{
PERCEPTUAL LEARNING: DIFFERENTIATION OR ENRICHMENT? ${ }^{1}$
}

\author{
JAMES J. GIBSON AND ELEANOR J. GIBSON
}

Cornell. University

The term "perceptual learning" means different things to different psychologists. To some it implies that human perception is, in large part, learned-that we learn to see depth, for instance, or form, or meaningful objects. In that case the theoretical issue involved is how much of perception is learned, and the corresponding controversy is that of nativism or empiricism. To others the term implies that human learning is in whole or part a matter of perception-that learning depends on comprehension, expectation, or insight, and that the learning process is to be found in a central process of cognition rather than in a motor process of performance. In this second case, the theoretical issue involved is whether or not one has to study a man's perceptions before one can understand his behavior, and the controversy is one of long standing which began with oldfashioned behaviorism.

These two sets of implications are by no means the same, and the two problems should be separated. The problem of the role of learning in perception has to do with perception and the effect of past experience or practice on it. The problem of the role of perception in learning has to do with behavior and the question of whether we can learn to do something by perceiving, or whether we can only learn by doing it. The questions, then, are these: (a) In

I This paper is a revision, with added experimental material, of one given in May 1953 at a symposium on the psychology of learning basic to problems of military training (8) conducted by the Panel on Training and Training Devices of the Research and Development Board, Washington, D. C. what sense do we learn to perceive? (b) In what sense can we learn by perceiving? Both questions are important for the practical problems of education and training, but this paper will be concerned with the former.

\section{In What Sense Do We Learn to Perceive?}

This question has roots in philosophy and was debated long before experimental psychology came of age. Does all knowledge (information is the contemporary term) come through the sense organs or is some knowledge contributed by the mind itself? Inasmuch as sensory psychology has been unable to explain how as much information about the world as we manifestly do obtain is transmitted by the receptors, some theory is required for this unexplained surplus. There has been a variety of such theories ever since the days of John Locke. An early notion was that the surplus is contributed by the rational faculty (rationalism). Another was that it comes from innate ideas (nativism). In modern times there have been few adherents to these positions. The most popular theory over the years has been that this supplement to the sensations is the result of learning, and that it comes from past experience. A contemporary formula for this explanation is that the brain stores information-possibly in the form of traces or memory images, but conceivably as attitudes, or mental sets, or general ideas, or concepts. This approach has been called empiricism. It preserves the dictum that all knowledge comes from experience by assum- 
ing that past experience somehow gets mixed with present experience. It assumes, in other words, that experience accumulates, that traces of the past somehow exist in our perception of the present. One of its high-water marks was Helmholtz's theory of unconscious inference, which supposes that we learn to see depth by interpreting the clues furnished by the depthless sensations of color. Another was Titchener's context theory of meaning, which asserts that we learn to perceive objects when a core of sensations acquires by association a context of memory images.

Over a generation ago this whole line of thought was challenged by what seemed to be a different explanation for the discrepancy between the sensory input and the finished percept-the theory of sensory organization. The gestalt theorists made destructive criticisms of the notion of acquired linkages among sensory elements and their traces. Instead they asserted that the linkages were intrinsic, or that they arose spontaneously, taking visual forms as their best example. Perception and knowledge, they said, were or came to be structured.

The theory of sensory organization or cognitive structure, although it generated a quantity of experimentation along new lines, has not after 30 years overthrown the theory of association. In this country the old line of empiricist thinking has begun to recover from the critical attack, and there are signs of a revival. Brunswik (2, pp. $23 \mathrm{ff}$.) has followed from the start the line laid down by Helmholtz. Ames and Cantril and their followers have announced what might be called a neoempiricist revelation $(3,11,14)$. Other psychologists are striving for a theoretical synthesis which will include the lessons of gestalt theory but retain the notion that perception is learned. Tolman, Bartlett, and Woodworth began the trend.
Leeper took a hand in it at an early date (15). The effort to reconcile the principle of sensory organization with the principle of determination by past experience has recently been strenuously pursued by Bruner (1) and by Postman (16). Hilgard seems to accept both a process of organization governed by relational structure and a process of association governed by the classical laws (10). Hebb has recently made a systematic full-scale attempt to combine the best of gestalt theory and of learning theory at the physiological level (9). What all these theorists seem to us to be saying is that the organization process and the learning process are not inconsistent after all, that both explanations are valid in their way, and that there is no value in continuing the old argument over whether learning is really organization or organization is really learning. The experiments on this issue (beginning with the Gottschaldt experiment) were inconclusive, and the controversy itself was inconclusive. Hence, they argue, the best solution is to agree with both sides.

It seems to us that all extant theories of the perceptual process, including those based on association, those based on organization, and those based on a mixture of the two (including attitudes, habits, assumptions, hypotheses, expectation, images, contexts, or inferences) have at least this feature in common: they take for granted a discrepancy between the sensory input and the finished percept and they aim to explain the difference. They assume that somehow we get more information about the environment than can be transmitted through the receptor system. In other words, they accept the distinction between sensation and perception. The development of perception must then necessarily be one of supplementing or interpreting or organizing. 
Let us consider the possibility of rejecting this assumption altogether. Let us assume tentatively that the stimulus input contains within it everything that the percept has. What if the flux of stimulation at receptors does yield all the information anyone needs about the environment? Perhaps all knowledge comes through the senses in an even simpler way than John Locke was able to conceive-by way of variations, shadings, and subtleties of energy which are properly to be called stimuli.

\section{The Enrichment Theory versus the SPECIFICITY TheORY}

The entertaining of this hypothesis faces us with two theories of perceptual learning which are clear rather than vague alternatives. It cuts across the schools and theories, and presents us with an issue. Is perception a creative process or is it a discriminative process? Is learning a matter of enriching previously meagre sensations or is it a matter of differentiating previously vague impressions? On the first alternative we might learn to perceive in this sense: that percepts change over time by acquiring progressively more memory images, and that a context of memories accrues by association to a sensory core. The theorist can substitute attitudes or inferences or assumptions for images in the above Titchenerian proposition, but perhaps all this does is to make the theory less neat while making the terminology more fashionable. In any case perception is progressively in decreasing correspondence with stimulation. The latter point is notable. Perceptual learning, thus conceived, necessarily consists of experience becoming more imaginary, more assumptive, or more inferential. The dependence of perception on learning seems to be contradictory to the principle of the dependence of perception on stimulation.
On the second alternative we learn to perceive in this sense: that percepts change over time by progressive elaboration of qualities, features, and dimensions of variation; that perceptual experience even at the outset consists of a world, not of sensation, and that the world gets more and more properties as the objects in it get more distinctive; finally, that the phenomenal properties and the phenomenal objects correspond to physical properties and physical objects in the environment whenever learning is successful. In this theory perception gets richer in differential responses, not in images. It is progressively in greater correspondence with stimulation, not in less. Instead of becoming more imaginary it becomes more discriminating. Perceptual learning, then, consists of responding to variables of physical stimulation not previously responded to. The notable point about this theory is that learning is always supposed to be a matter of improvement-of getting in closer touch with the environment. It consequently does not account for hallucination or delusions or, in fact, for any kind of maladjustment.

The latter kind of theory is certainly worth exploring. It is not novel, of course, to suggest that perceptual development is a matter of differentiation. As phenomenal description this was asserted by some of the gestalt psychologists, notably Koffka and Lewin. (Just how differentiation was related to organization, however, was not clear.) What is novel is to suggest that perceptual development is always a matter of the correspondence between stimulation and perception-that it is strictly governed by the relationships of the perceiver to his environment. The rule would be that, as the number of distinct percepts a man can have increases, so also the number of different physical objects to which they are specific in- 
creases. An example may clarify this rule. One man, let us say, can identify sherry, champagne, white wine, and red wine. He has four percepts in response to the total possible range of stimulation. Another man can identify a dozen types of sherry, each with many varieties, and numerous blends, and so on for the others. He has four thousand percepts in response to the range of stimulation. The crucial question to ask about this example of differentiated perception is its relation to stimulation.

Stimulus is a slippery term in psychology. Properly speaking stimulation is always energy at receptors, that is, proximal stimulation. An individual is surrounded by an array of energy and immersed in a flow of it. This sea of stimulation consists of variation and invariants, patterns and transformations, some of which we know how to isolate and control and others of which we do not. An experimenter chooses or constructs a sample of this energy when he performs a psychological experiment. But it is easy for him to forget this fact and to assume that a glass of wine is a stimulus when actually it is a complex of radiant and chemical energies which is the stimulus. When the psychologist refers to stimuli as cues, or clues, or carriers of information he is skipping lightly over the problem of how stimuli come to function as cues. Energies do not have cue properties unless and until the differences in energy have correspondingly different effects in perception. The total range of physical stimulation is very rich in complex variables and these are theoretically capable of becoming cues and constituting information. This is just where learning comes in.

All responses to stimulation, including perceptual responses, manifest some degree of specificity, and, inversely, some degree of nonspecificity. The gentleman who is discriminating about his wine shows a high specificity of perception, whereas the crude fellow who is not shows a low specificity. A whole class of chemically different fluids is equivalent for the latter individual; he can't tell the difference between claret, burgundy, and chianti; his perceptions are relatively undifferentiated. What has the first man learned that the second man has not? Associations? Memories? Attitudes? Inferences ? Has he learned to have perceptions instead of merely sensations? Perhaps, but a simpler statement might be made. The statement is that he has learned to taste and smell more of the qualities of wine, that is, he discriminates more of the variables of chemical stimulation. If he is a genuine connoisseur and not a fake, one combination of such variables can evoke a specific response of naming or identifying and another combination can evoke a different specific response. He can consistently apply nouns to the different fluids of a class and he can apply adjectives to the differences between the fluids.

The classical theory of perceptual learning, with its emphasis on subjective determination of perception in contrast to stimulus determination, gets its plausibility from experiments on errors in form perception, from the study of illusions and systematic distortions, and from the fact of individual differences in and social influences on perception. The learning process is assumed to have occurred in the past life of the experimental subject; it is seldom controlled by the experimenter. These are not learning experiments insofar as they do not control practice or take measures before and after training. True perceptual learning experiments are limited to those concerned with discrimination.

One source of evidence about discriminative learning comes from the study of the cues for verbal learning. 
The analysis of these cues made by one of the authors in terms of stimulus generalization and differentiation (4) suggests the present line of thought. It has also led to a series of experiments concerned with what we call identifying responses. Motor reactions, verbal reactions, or percepts, we assume, are identifying responses if they are in specific correspondence with a set of objects or events. Code learning (13), aircraft recognition (7), and learning to name the faces of one's friends are all examples of an increasingly specific correspondence between the items of stimulation presented and the items of response recorded. As a given response gains univocality, the percept is reported to gain in the feeling of familiarity or recognition and to acquire meaning.

\section{AN Illustrative Experiment ${ }^{2}$}

In order to provide a clear example of such learning, we studied the development of a single identifying response. The $S$ was presented with a visual item consisting of a nonsense "scribble"; his recognition of it was tested when it was interspersed in a series of similar scribbles, and then the single showing and the multiple presentation were repeated until the item could be identified. We devised a set of 17 scribbles intended to be indistinguishable from the critical item on the first trial, and another set of 12 items intended to be distinguishable from the critical item on the first trial.

The items which had to be differentiated are shown in Fig. 1. The critical item, a four-coil scribble, is in the center and 16 other items are arranged outward from it. The eighteenth item (a reversal of the critical item) is not shown. It may be noted that there are three dimensions of variation from the critical item: (a) number of coils-three, four, or five, (b) horizontal compression or stretching, and (c) orientation or right-left reversal. The latter two kinds of variation were produced by photographic transforma-

2 This experiment was first reported at the meeting of the American Psychological Association in September 1950 in a paper read by Eleanor J. Gibson, and an abstract has been published (6).

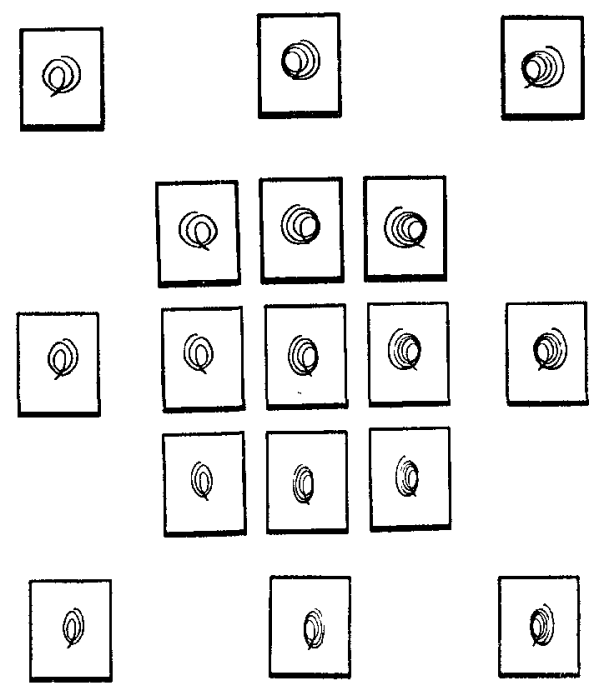

FIG. 1. Nonsense items differing in three dimensions of variation.

tion. There are three degrees of coil frequency, three degrees of compression, and two types of orientation, which yields 18 items. Since one of these is the critical item, 17 remain for use in the experiment. The reader may observe that when these differences are verbally specified and the figures are displayed for immediate comparison, as in Fig. 1 , they are clearly distinguishable. The $S$ s of the experiment, however, saw the items only in succession.

The 12 additional items presented on each recognition trial are shown in Fig. 2. Each differs from every other and from all of the

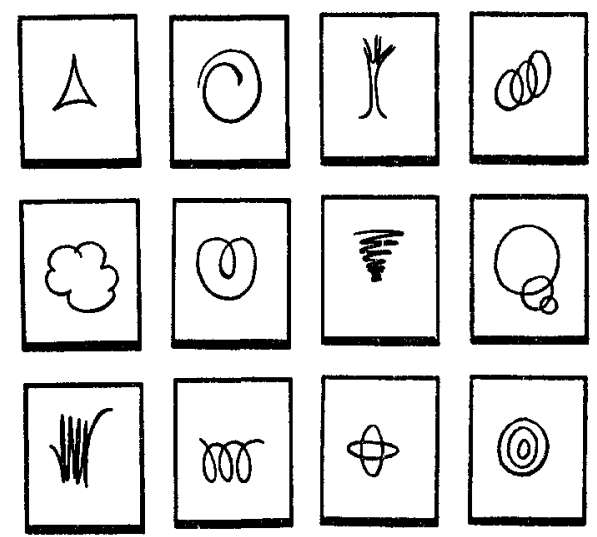

FIG. 2. Nonsense items differing in many dimensions of variation. 
set of 18 . The differences from the scribbles were intended to be sufficient to make them appear different at the outset to $S$ s with a normal amount of experience with drawn forms. The 30 items (12 plus 18) were printed photographically on stiff 2 in. $\times 4$ in. cards with black borders, and made into a pack. The material available for any one learning trial consisted of the critical item plus a shuffled pack of cards among which were interspersed four replicas of the critical item.

The $S$ was shown the critical item for about $5 \mathrm{sec}$. and told that some of the items in the pack would be exactly like the one shown. The series of 34 was then presented each with a 3-sec. exposure and $S$ was asked to report which of them were the same figure. The identifying response recorded was any report such as "that's it" or "this is the one I saw before." The $S$ was never told whether an identification was correct or incorrect. A record was kept not only of the identifying responses, but also of any spontaneous $d e$ scriptions offered by $S$, which were later classified as naming responses and qualifying responses.

At the end of the first trial the critical figure was presented a second time and another shuffled pack was run through. The procedure of examining a figure and then trying to identify it when mixed with a series including figures of both great and little similarity was continued until $S$ made only the four correct identifications in one trial. Three groups took part in the experiment: 12 adults, 10 older children ( $8^{1 / 2}$ to 11 years), and 10 younger children (6 to 8 years).
Results. In this experiment, learning is taken to be an increase-in the specificity of an identifying response or, in other words, a decrease in the size of the class of items that will elicit the response. The data therefore consist of the number of items (out of a probable maximum of 17) reacted to as if they were the critical figure. As will be evident, this class of undifferentiated items was reduced as a result of repetition. The three groups of $S$ s, however, began to learn at very different levels and learned at very different rates. The results are given in Table 1. For adults, the class of undifferentiated items at the outset was small (Mean $=3.0)$, and only a few trials were needed before this class was reduced to the critical item alone $($ Mean $=3.1)$. Two of these adults were able to make no other than correct identifying responses on the first trial. Both were psychologists who could have had previous acquaintance with nonsense figures. The learning task was so easy for this group that not much information about the learning process could be obtained. At the other extreme, however, the younger children "recognized" nearly all of the scribbles on the first trial (Mean $=13.4)$, which

TABLE 1

InCRease in Specificity of an Identifying Response for Three Age Groups

\begin{tabular}{|c|c|c|c|}
\hline Variable & $\begin{array}{c}\text { Adults } \\
(N=12)\end{array}$ & $\begin{array}{c}\text { Older } \\
\text { Children } \\
(N=10)\end{array}$ & $\begin{array}{c}\text { Younger } \\
\text { Children } \\
(N=10)\end{array}$ \\
\hline $\begin{array}{l}\text { Mean number of undifferentiated items on first } \\
\text { trial } \\
\text { Mean number of trials required for completely } \\
\text { specific response }\end{array}$ & $\begin{array}{l}3.0 \\
3.1\end{array}$ & 4.7 & $\begin{array}{l}13.4 \\
6.7^{*}\end{array}$ \\
\hline $\begin{array}{l}\text { Percentage of erroneous recognitions for items } \\
\text { differing in one quality } \\
\text { Percentage of erroneous recognitions for items } \\
\text { differing in two qualities } \\
\text { Percentage of erroneous recognitions for items } \\
\text { differing in three qualities }\end{array}$ & $\begin{array}{l}17 \\
2 \\
0.7\end{array}$ & $\begin{array}{r}27 \\
7 \\
2\end{array}$ & $\begin{array}{l}53 \\
35 \\
28\end{array}$ \\
\hline
\end{tabular}

* Only two of the younger children achieved a completely specific identification. The mean number of undifferentiated items on the last trial was still 3.9. 
is to say that the class of undifferentiated items was large. The number of trials needed to reduce this class to the correct item was so great that most of the $S$ s could not be required to complete the experiment. Two out of 10 reached the criterion, but for the remainder the trials had to be stopped for reasons of fatigue. After an average of 6.7 trials the mean number of undifferentiated items was still 3.9. One child had so much difficulty with the task that $E$ finally gave differential reinforcement by saying "right" or "wrong" after each presentation of a card. Although this procedure helped, wholly specific identifications were never achieved. The failures of the younger children to discriminate did not seem to be due merely to "inattention"; they understood that they were to select only the figures which were exactly the same as the critical figure.

For the older children (between $81 / 2$ and 11 years of age) the results were intermediate between these extremes. For them the particular task and the particular items were neither too hard nor too easy. The average number of undifferentiated items on the first trial was 7.9 , and all children succeeded in reducing this to a single item after a mean of 4.7 trials.

Table 1 also indicates for each group an important fact about the unspecific responses: they tend to occur more often as the differences between the test item and the critical item become fewer. As Fig. 1 shows, a given scribble may differ in one quality or dimension (thickness, coil frequency, or orientation), or in tzeo of these qualities, or in all three of them. Five of the scribbles differ in one feature, eight differ in two features, and four differ in three features. It will be recalled that the 12 additional forms shown in Fig. 2 differed from the critical item with respect to more than three features. Amount of difference can be usefully stated as number of differing qualities or, conversely, amount of sameness as the fewness of differing qualities. $^{3}$ The lower half of Table 1 gives the percentage of occurrence of false recognitions in the case of scribbles with one quality different, with two qualities different, and with three qualities different. These percentages are based on the number of times the items in question were presented during the whole series of trials. The "dissimilar" figures, which had many qualities different, yielded a zero percentage of false recognitions except for a few scattered instances among the younger children.

Discussion. The results show clearly that the kind of perceptual learning hypothesized has occurred in this experiment. A stimulus item starts out by being indistinguishable from a whole class of items in the stimulus universe tested, and ends by being distinguishable from all of them. The evidence for this assertion is that the specificity of $S$ 's identifying response has increased. What has happened to produce this result?

The Ss were encouraged to describe all the items of each series as they were presented, and a special effort was made to obtain and record these spontaneous verbal responses for seven of the older children. In general they tended to fall into two types, either naming responses or qualifying responses. Considering only the responses to the 17 scribbles, the record showed that the frequency of the latter type increased during the progress of learning. Examples of the former are nouns like figure 6, curl, spiral, scroll. Examples of the latter are adjectival phrases like too thin,

${ }^{8}$ Experiments on primary stimulus generalization have usually varied the magnitude of a single difference, not the number of differences, between the critical stimulus and the undifferentiated stimulus. However, our method of quantifying "amount of difference" has much to recommend it. 
rounder, reversed. It is notable that the latter are responses not to the item as such but to the relation between it and the critical item. They are analogous to differential judgments in a psychophysical experiment. An adjective, in general, is a response which is specific not to an object but to a property of two or more objects. It is likely, then, that the development of a specific response to an item is correlated with the development of specific responses to the qualities, dimensions, or variables that relate it to other items. The implication is that, for a child to identify an object, he must be able to identify the differences between it and other objects, or at least that when he can identify an object he also can identify its properties.

The verbal reactions of the children to the 17 scribbles, both naming and qualifying, could be categorized by $E$ as specific or nonspecific to the item in question. These judgments were necessarily subjective, but they were carried out with the usual precautions. Although a single adjective cannot be specific to a single item, a combination of adjectives can be. An example of a nonspecific reaction is "another curlicue," and of a specific reaction is "this one is thinner and rounder." The latter sort may be considered a spontaneously developing identifying reaction, not of the "that's it" type, it is true, but nevertheless fulfilling our definition. The mean number of such verbal reactions on the first trial was 7.7 out of 17 , or 45 per cent. The mean number of such reactions on the last trial was 16.5 , or 97 per cent. This suggests that, as a single identifying response becomes increasingly specific to one member of a group of similar items, verbal identifying responses also tend to become specific to the other members of the group. As the class of indistinguishable items which will elicit one response is dimin- ished, the number of responses which can be made to the class increases.

\section{Other Evidence}

Another source of experimental evidence about perceptual learning comes from psychophysics. Contrary to what might be expected, psychophysical experimenters over the years have shown a lively interest in perceptual learning, or at least in the bettering of perceptual judgments with practice. One of the authors has recently surveyed this neglected literature insofar as it concerns improvement of perception or increase in perceptual skills (5). There is a great quantity of evidence about progressive change in acuity, variability, and accuracy of perception, including both relative judgments and absolute judgments. It proves beyond a shadow of doubt that the notion of fixed thresholds for a certain set of innate sensory dimensions is oversimplified. Discrimination gets better with practice, both with and without knowledge of results. An example may be taken from the two-point threshold on the skin.

As long ago as 1858 it was discovered that there is a certain distance at which two points are felt double by a blindfolded subject that is characteristic of the area of the skin tested. At the same time, it was found that only a few hours of practice in this discrimination had the effect of reducing the distance to half of what it had been (17). Later experiments showed that the lowering of the threshold continued slowly for thousands of trials; for instance, it might go from $30 \mathrm{~mm}$. to $5 \mathrm{~mm}$. during four weeks of training. Moreover, the improved discrimination transferred to other untrained areas of the skin, transfer being nearly complete for the bilaterally symmetrical area. It was found that blind subjects had very much lower thresholds than seeing subjects even at the beginning of testing 
$(12,18)$. The experimental improvement was largely lost after a period of disuse. It seemed to depend on confirmation or correction of the judgment, or, in the absence of that, on the development of a sort of scale from "close together" to "far apart" (5). It is clear that any theory of supposedly distinct sensations of oneness and twoness never had any support from these data. As one writer put it, the observer adopts different and finer criteria of doubleness. What might these criteria be? We suggest that the stimulation is complex, not simple, and that the observer continues to discover higher-order variables of stimulation in it. The percept becomes differentiated.

\section{Conclusson}

There is no evidence in all of this literature on perceptual learning, nor is there evidence in the experiment reported in the last section, to require the theory that an accurate percept is one which is enriched by past experience, whereas a less accurate percept is one not enriched by past experience. Repetition or practice is necessary for the development of the improved percept, but there is no proof that it incorporates memories. The notion that learned perception is less and less determined by external stimulation as learning progresses finds no support in these experiments. The observer sees and hears more, but this may be not because he imagines more, or infers more, or assumes more, but because he discriminates more. He is more sensitive to the variables of the stimulus array. Perhaps the ability to summon up memories is merely incidental to perceptual learning and the ability to differentiate stimuli is basic. Perhaps the dependence of perception on learning and the dependence of perception on stimulation are not contradictory principles after all.
This theoretical approach to perceptual learning, it must be admitted, has points of weakness as well as points of strength. It accounts for veridical perception, but it does not account for misperception. It says nothing about imagination or fantasy, or wishful thinking. It is not an obviously useful approach for the study of abnormal behavior or personality, if one is convinced that a man's perceptions are the clues to his motives. But if one is concerned instead with the practical question of whether training can affect favorably a man's perception of the world around him, a very productive field for theory and experiment is opened up.

\section{REFERENCES}

1. Bruner, J. S. Personality dynamics and the process of perceiving. In $R$. $R$. Blake \& G. V. Ramsey (Eds.), Perception: an approach to personality. New York: Ronald, 1951. Pp. 121-147.

2. Brunswik, E. The conceptual framework of psychology. Int. Encycl. unif. Sci., 1952, 1, No. 10.

3. Cantril, H., Ames, A., Jr., Hastorf, A. H., \& Irtelson, W. H. Psychology and scientific research. Science, 1949, 110, 461-464, 491-497, 517-522.

4. Gibson, Eleanor J. A systematic application of the concepts of generalization and differentiation to verbal learning. Psychol. Rev., 1940, 47, 196-229.

5. Gibson, Eleanor J. Improvement in perceptual judgments as a function of controlled practice or training. Psychol. Bull., 1953, 50, 401-431.

6. Grbson, Eleanor J., \& Gibson, J. J. The identifying response: a study of a neglected form of learning. Amer. Psychologist, 1950, 7, 276. (Abstract)

7. Gibson, J. J. (Ed.) Motion picture testing and research. Washington, D. C.: Government Printing Office, 1947. ( $A A F$ Aviat. Psychol. Program Res. Rep., No. 7.)

8. Gibson, J. J., \& Gibson, Eleanor J. Perceptual learning in relation to training. In Symposium on psychology of learning basic to military training problems. Dept. of Defense, HR-HTD-201-1, 1953, 151-159.

9. HeBв, D. O. The organization of behavior. New York: Wiley, 1949. 
10. HIIGard, E. R. The role of learning in perception. In R. R. Blake \& G. V. Ramsey (Eds.), Perception: an approach to personality. New York: Ronald, 1951. Pp. 95-120.

11. ITtesson, W. H. The constancies in perceptual theory. Psychol. Rev., 1951, 58, 285-294.

12. Jastrow, J. Psychological notes on Helen Keller. Psychol. Rev., 1894, 1, 356-362.

13. Keller, F. S. Studies in International Morse Code. I. A new method of teaching code reception. J. appl. Psychol, 1943, 27, 407-415.

14. KitPaTRICK, F. P. Human behavior from the transactional point of view. Hanover, N. H.: Institute for Associated Research, 1952.
15. LEEPER, R. A study of a neglected portion of the field of learning-the development of sensory organization. $J$. genet. Psychol., 1935, 46, 41-75.

16. Postman, L. Toward a general theory of cognition. In J. H. Rohrer \& M. Sherif (Eds.), Social psychology at the crossroads. New York: Harper, 1951. Pp. 242-272.

17. VolkmanN, A. Ueber den Einfluss der Uebung auf das Erkennen raumlicher Distanzen. Ber. d. Sachs. Ges. d. Wiss., math. phys. Abth., 1858, 10, 38-69.

18. Whipple, G. M. Manual of mental and physical tests. Part I. Simpler processes. Baltimore: Warwick and York, 1924.

(Received January 8, 1954) 